\title{
Flotation Behavior of Arsenopyrite and Pyrite, and Their Selective Separation
}

\author{
Kyuhyeong Park, Junhyun Choi, Allan Gomez-Flores and Hyunjung Kim* \\ Department of Mineral Resources and Energy Engineering, Chonbuk National University, \\ 567, Baekje-daero, Deokjin-gu, Jeonju, Jeonbuk 556-756, Republic of Korea
}

\begin{abstract}
This study investigated the effect of $\mathrm{pH}$ and pulp potential $\left(E_{\mathrm{H}}\right)$ on the floatability of arsenopyrite and pyrite, which are single minerals, in Hallimond tube, by using xanthate as a collector. On this basis, the study further investigated the selectivity index of arsenopyrite and pyrite, using a mixed sample of arsenopyrite and pyrite. To examine the flotation behavior of each mineral by $\mathrm{pH}$ change, flotation was carried out at pH 4 and $\mathrm{pH}$ 10. The test results showed arsenopyrite had higher floatability at $\mathrm{pH} \mathrm{4,} \mathrm{regardless} \mathrm{of} \mathrm{the} \mathrm{potassium} \mathrm{ethyl} \mathrm{xanthate} \mathrm{(PEX)}$ concentration. This is because xanthate ion was oxidized to be stable dixanthogen, which was well adsorbed onto arsenopyrite surface, due to the high $E_{\mathrm{H}}$ of pulp. Meanwhile, arsenopyrite had relatively lower floatability at $\mathrm{pH} 10$ than at $\mathrm{pH}$, which was because the dixanthogen remained unstable, and was not adsorbed onto the arsenopyrite surface, due to the relatively low $E_{\mathrm{H}}$ of pulp. Pyrite had low floatability at both pH 4 and $\mathrm{pH}$ 10. Just as for arsenopyrite, the result for $\mathrm{pH} 10$ was caused by the low $E_{\mathrm{H}}$ of pulp. Yet, interestingly enough, different from the case of arsenopyrite, pyrite at $\mathrm{pH} 4$ had low floatability, despite its high $E_{\mathrm{H}}$. FTIR analysis was performed, to examine the reason for such contradictory behavior. The analysis result showed that this was caused by poor adsorption with xanthate, due to sulfate ion $\left(\mathrm{SO}_{4}{ }^{2-}\right)$ that was generated by the oxidation of pyrite surface in reaction with oxygen in pulp at $\mathrm{pH} 4$. To further investigate the selectivity index (i.e., the pyrite recovery/ arsenopyrite recovery ratio) of arsenopyrite and pyrite, additional flotation tests were carried out on mixed sample of the two minerals. Different from the flotation behavior of single minerals, the results showed that the recovery of arsenopyrite was lower than that of pyrite, and the selectivity index of arsenopyrite and pyrite was the highest when the PEX concentration was the lowest. Such a different trend in flotation behavior of the mixed sample from the flotation behavior of the single minerals was because the surface oxidation reaction of arsenopyrite, which was more affected by $E_{\mathrm{H}}$ among the mixed arsenopyrite and pyrite, generated ferric arsenate, a hydrophilic compound, on the surface of arsenopyrite, resulting in poor adsorption with xanthate; in turn, this depressed the floatability of arsenopyrite.
\end{abstract}

[doi:10.2320/matertrans.M2014369]

(Received October 17, 2014; Accepted January 6, 2015; Published February 13, 2015)

Keywords: flotation, arsenopyrite, pyrite, selective separation

\section{Introduction}

Arsenic in sulfide minerals (arsenopyrite, arsenian-pyrite, etc.), sulfosalts minerals (tennantite, enargite, etc.), and arsenates minerals (scorodite) causes serious environmental pollution, if it is exposed to nature by acid mine drainage; and if it is exposed to human, it damages lung, liver and kidney, causing skin cancer. ${ }^{1-5)}$ Thus, it is classified as a toxic element. As such arsenic is a penalty element having a harmful effect on the environment and human, refineries strictly restrict the arsenic contents in concentrate to $0.2-$ 0.3 mass \%. ${ }^{6}$ ) To satisfy such regulation, arsenic is in general removed through a metallurgical process (e.g., hydrometallurgy or pyrometallurgy). ${ }^{7,8)}$ However, such methods require additional treatment cost, resulting in financial loss. ${ }^{7,8)}$ So, there are active studies on the selective separation of arsenic at the flotation process, a previous stage of the metallurgical process. $^{9-19)}$

There are previous studies in which arsenic sulfide was selectively separated in the flotation process, with xanthate as a collector. ${ }^{9-19)}$ Of these, the majority used a selective depression method of arsenic sulfide. For example, several studies reported that magnesia mixture could be used as a depressant to inhibit xanthate adsorption onto arsenic sulfides, by forming hydrophilic compound, such as $\mathrm{AsO}_{4} \mathrm{NH}_{4} \mathrm{Mg} \cdot 6 \mathrm{H}_{2} \mathrm{O}$, on the surface of arsenic sulfide. ${ }^{9,10)}$ In other methods, Menacho et al. (1993), Huch (1994) and Fornasiero et al. (2001) performed pre-oxidation at the preconditioning stage to selectively separate arsenic, ${ }^{11-13)}$ and Huch (1994) reported the separation of chalcocite $\left(\mathrm{Cu}_{2} \mathrm{~S}\right)$

*Corresponding author, E-mail: kshjkim@jbnu.ac.kr from enargite $\left(\mathrm{Cu}_{3} \mathrm{AsS}_{4}\right)$, using hydrogen peroxide $\left(\mathrm{H}_{2} \mathrm{O}_{2}\right)$, which was an oxidizing agent. ${ }^{12)}$ According to the above results, in the flotation process, oxidation of the mineral surface is very important in sulfide mineral separation; and oxide or hydroxide layers that are formed by the oxidation of mineral surface inhibited xanthate adsorption, which indicated the depression of arsenic sulfide in flotation. Meanwhile, existing studies that selectively separated arsenic sulfide by controlling pulp $\mathrm{pH}$ employed a different principle of oxidation of arsenic sulfide surface by the change of pulp $\mathrm{pH}$. For instance, Kantar (2002) reported that elemental sulfur $\left(\mathrm{S}^{0}\right)$ formed on enargite surface by surface oxidation within the range of acidic $\mathrm{pH}$, which increased natural floatability. ${ }^{14)}$ Lopez (2006) reported that, at alkali $\mathrm{pH}$, arsenic oxide, such as arsenate anions $\left(\mathrm{H}_{2} \mathrm{AsO}_{4}{ }^{-}, \mathrm{HAsO}_{4}{ }^{2-}\right)$, formed on the surface of arsenopyrite (FeAsS), and such arsenic oxide inhibited the adsorption of xanthate on arsenopyrite surface, which resulted in the depression of arsenopyrite. $^{15)}$

Although much effort has been devoted to separating arsenic sulfide using the flotation process, it is known to be difficult to separate arsenic sulfide from sulfide that does not contain arsenic using flotation, due to their similar surface properties. ${ }^{16,17)}$ In particular, as the surface properties of arsenopyrite and pyrite $\left(\mathrm{FeS}_{2}\right)$ are very similar, it is difficult to simply separate them using flotation. Only a few studies, to the best of our knowledge, focused on the separation of arsenopyrite and pyrite in an arsenopyrite-pyrite or an arsenopyrite-pyrite-quartz system. ${ }^{18,19)}$ For example, Sirkeci (2000) carried out bench-scale flotation tests using hexyl thioethylamine as a collector in an arsenopyrite-pyrite-quartz system, and it was found that the selectivity obtained by 
using hexyl thioethylamine was greater than that by potassium amyl xanthate (PAX) and that maximum selectivity index was about 4.2. ${ }^{18)}$ Taply and Yan (2003) conducted a series of bench-scale flotation tests using an arsenopyritepyrite mixture to find an optimum condition for maximum selectivity where a magnesia mixture was used as a depressant, and they reported the maximum selectivity index of 2.1. ${ }^{19)}$ Such studies, however, more likely focused on practical aspect (i.e., performance of a flotation process, such as recovery and grade) and less on mechanistic understanding of the process. Since the information on flotation chemistry (e.g., minerals' surface chemistry, pulp chemistry) is very critical to further improve the selectivity and/or better control the process in an arsenopyrite-pyrite system, more study on this is required.

Therefore, our study was designed to gaining insight on the effect of $\mathrm{pH}$ and pulp potential $\left(E_{\mathrm{H}}\right)$ on the floatability of arsenopyrite and pyrite, which are single minerals, in a wellcontrolled system (i.e., Hallimond system) by using xanthate as a collector, and further to finding the optimum condition for maximum selectivity in an arsenopyrite-pyrite system based on the information obtained using single minerals. For this purpose, surface characterization analyses (e.g., FTIR, $\mathrm{XRD)}$ as well as a Hallimond system were employed to investigate the relationship between the change of surface properties of each mineral, and their flotation behavior.

\section{Materials and Methods}

\subsection{Materials and reagents}

The natural specimens of arsenopyrite (FeAsS) and pyrite $\left(\mathrm{FeS}_{2}\right)$ used in this study were purchased from Hong Yuan Industry \& Trade in China. Inductively Coupled Plasma (ICP) (Optima 5300PV, PerkinElmer Inc., USA) and X-ray Diffraction (XRD) (X'pert Pro, PANalytical, Netherlands) were employed to analyze the chemical composition and mineralogy of each sample (Fig. 1). The results of ICP analysis showed the chemical composition of arsenopyrite had a composition ratio of $\mathrm{Fe} 27.79$ mass \%, As 35.11 mass\%, and S 16.17 mass $\%$; and the chemical composition of pyrite had Fe 40.86 mass $\%$, and S 46.02 mass $\%$. XRD analysis results were consistent with those from ICP analysis. Here, it should be noted that although the peak of quartz was observed for both minerals, the effect of minimal amount of silica on the present study is negligible due to the unfavorable interaction between quartz and xanthate as supported by many previous studies. ${ }^{20,21)}$ To perform the flotation experiment, arsenopyrite and pyrite were crushed under 8 mesh (2.36 mm, Tyler Standard) using a jaw and cone crusher, and a single disc mill was used to grind it to have a particle size distribution of $-105+150$ mesh $(106-150 \mu \mathrm{m}$, Tyler Standard). To prevent mineral surface oxidation, the sample was preserved at freezing status. The collector used in this study was potassium ethyl xanthate $\left(\mathrm{C}_{2} \mathrm{H}_{5} \mathrm{OCS}_{2} \mathrm{~K}\right.$, SigmaAldrich) with $96 \%$ purity level, and it was mixed with deionized (DI) water (DO level $=\sim 7.8 \mathrm{mg} / \mathrm{L}$, Milli-Q, Plus, Millipore Ltd., UK) to prepare stock solution that was diluted for use in the desired experiments. To minimize natural degradation of the xanthate solution, new stock solution was prepared on the date of the test. Fisher Scientific's $0.1 \mathrm{M}$
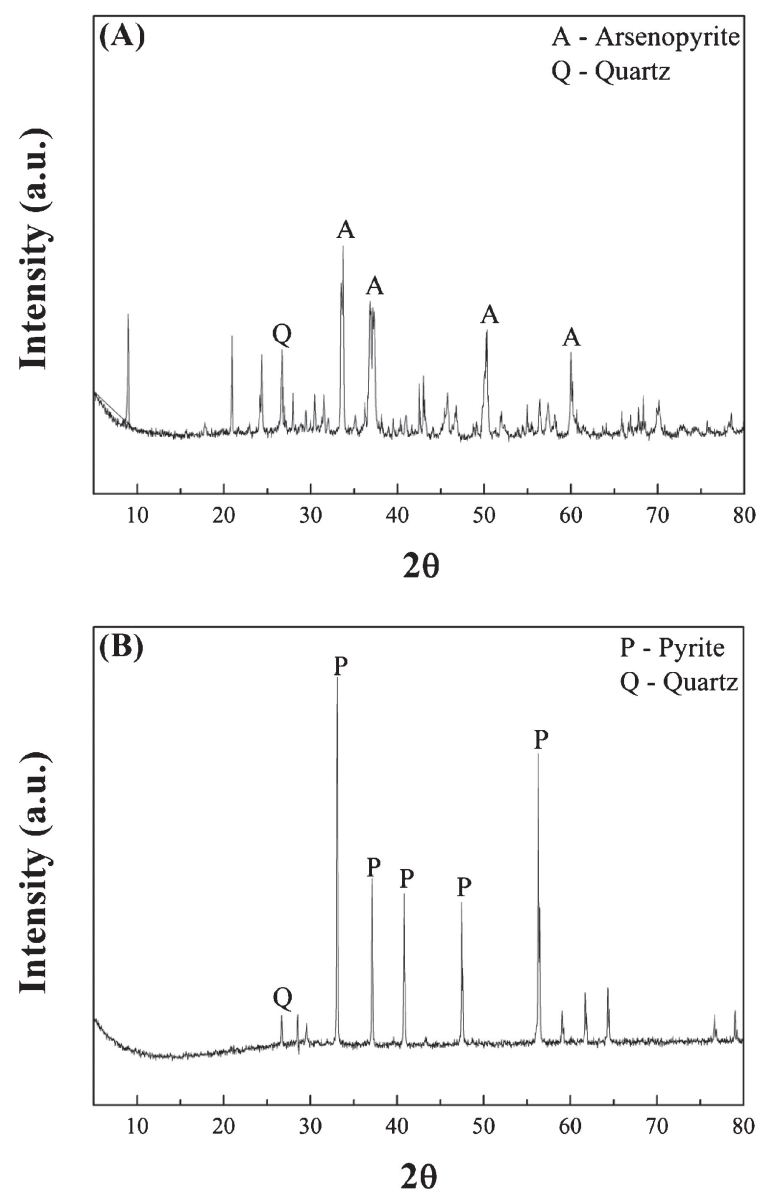

Fig. 1 XRD patterns of (A) arsenopyrite (FeAsS), and (B) pyrite $\left(\mathrm{FeS}_{2}\right)$.

hydrochloric acid $(\mathrm{HCl})$ and $0.1 \mathrm{M}$ sodium hydroxide $(\mathrm{NaOH})$ were used as a $\mathrm{pH}$ regulator.

\subsection{Xanthate adsorption and measurement of pulp potential $\left(E_{\mathrm{H}}\right)$ and $\mathrm{pH}$}

To investigate the effect of surface property change of arsenopyrite and pyrite on the flotation efficiency, each sample of $1 \mathrm{~g}$ was mixed with DI water to prepare a suspension, and then the $\mathrm{pH}$ of the suspension was controlled for $15 \mathrm{~min}$ as 4 and 10 , using $0.1 \mathrm{M}$ hydrochloric acid $(\mathrm{HCl})$ or sodium hydroxide $(\mathrm{NaOH})$. Afterwards, for adsorption tests, the concentration of potassium ethyl xanthate (PEX) was fixed to $10^{-6}, 10^{-5}$, and $10^{-4} \mathrm{M}$, and $1 \mathrm{~h}$ conditioning was performed to achieve equilibrium condition. After conditioning, the $\mathrm{pH}$ and pulp potential $\left(E_{\mathrm{H}}\right)$ of each suspension was measured by $\mathrm{pH}$ electrode (Orion Triode $\mathrm{pH} / \mathrm{ATC} \mathrm{Comb} \mathrm{Ag} / \mathrm{AgCl}$ Electrode, Thermo Science) and redox electrode (Orion Sure-flow Comb Redox Electrode, Thermo Science). The $E_{\mathrm{H}}$ value was presented on the Standard Hydrogen Electrode (SHE) scale.

\subsection{FTIR measurements}

In order to investigate the change of surface property of arsenopyrite and pyrite during flotation tests, surface analysis was carried out using FTIR on conditioned mineral samples. Using mortar, samples were prepared to have a particle size distribution of -500 mesh $(25 \mu \mathrm{m}$, Tyler Standard). Sample of $1 \mathrm{~g}$ was mixed with DI water, and then the $\mathrm{pH}$ of the 
suspension was adjusted to 4 and 10. PEX was then added to keep the background concentration of $1 \times 10^{-6} \mathrm{M}$. The mixture was agitated for $1 \mathrm{~h}$. After agitation, the samples were filtered, using cellulose acetate membrane filter (ADVANTEC, Toyo Roshi Kaisha, Japan) with pore size $0.45 \mu \mathrm{m}$, and the separated particles were dried at room temperature $\left(25^{\circ} \mathrm{C}\right)$ for $24 \mathrm{~h}$. Afterwards, samples were mixed with potassium bromide $(\mathrm{KBr})$ pellets, and IR analysis was carried out in the $4000-400 \mathrm{~cm}^{-1}$ range, using an FTIR analyzer (Spectrum GX, Perkin-Elmer, USA).

\subsection{Microflotation tests}

To evaluate the flotation behavior of arsenopyrite and pyrite, the PEX concentration was changed to $10^{-6}, 10^{-5}$, and $10^{-4} \mathrm{M}$, and microflotation tests were carried out under pH 4 and 10. Mineral samples were adsorbed with PEX for $1 \mathrm{~h}$ at each test condition. After adsorption, the suspension was filtered to remove the remaining PEX, and then microflotation tests were performed on $1 \mathrm{~g}$ samples. Meanwhile, for the mixed sample of arsenopyrite and pyrite, the microflotation test was carried out on the $1 \mathrm{~g}$ sample mixed from two samples of $0.5 \mathrm{~g}$ each, by changing the PEX concentration to $5 \times 10^{-7}, 10^{-6}$, and $10^{-5} \mathrm{M}$. Mineral sample preparation for the mixed sample microflotation test was the same as for the single sample case. The microflotation test conditions are as below. $1 \mathrm{~g}$ of samples and $150 \mathrm{~mL}$ of DI water were injected into the Hallimond tube, and mixed at $340 \mathrm{rpm}$ using a magnetic stirrer bar during the experiment. Nitrogen gas of $99 \%$ or higher purity was injected at a speed of $30 \mathrm{~mL} / \mathrm{min}$, and the flotation time was fixed at $3 \mathrm{~min}$. All experiments were carried out at room temperature $\left(25^{\circ} \mathrm{C}\right)$, using an in-house Hallimond tube. ${ }^{22)}$ To determine the flotation efficiency, each floated and unfloated sample was filtered, and dried at room temperature for $12 \mathrm{~h}$. For the single minerals, the weights of floated and unfloated samples were measured to determine the floatability, and to obtain the flotation efficiency and selectivity index (i.e., pyrite recovery/arsenopyrite recovery ratio) of the mixed mineral sample. The metal contents were analyzed in the floated and unfloated samples, using ICP.

\section{Results and Discussion}

\subsection{Flotation behavior of arsenopyrite and pyrite}

To investigate the individual flotation behavior of arsenopyrite and pyrite, flotation tests were carried out by the change of xanthate concentration $\left(1 \times 10^{-6}-1 \times 10^{-4} \mathrm{M}\right)$ under $\mathrm{pH} 4$ and 10, and Fig. 2 shows the results. The results show that the floatabilities of arsenopyrite and pyrite at $\mathrm{pH} 4$ were relatively higher than those at $\mathrm{pH} 10$. When the floatabilities of arsenopyrite and pyrite at the same $\mathrm{pH}$ were compared, arsenopyrite had relatively higher floatability than pyrite. Specifically, the floatability of arsenopyrite at $\mathrm{pH} 4$ was $88 \%$ at a PEX concentration of $1 \times 10^{-6} \mathrm{M}, 92 \%$ at $1 \times 10^{-5} \mathrm{M}$, and $91 \%$ at $1 \times 10^{-4} \mathrm{M}$. The floatability of pyrite at $\mathrm{pH} 4$ was $11 \%$ at a PEX concentration of $1 \times$ $10^{-6} \mathrm{M}, 20 \%$ at $1 \times 10^{-5} \mathrm{M}$, and $94 \%$ at $1 \times 10^{-4} \mathrm{M}$. From the result of the flotation separation test, the floatability of arsenopyrite at $\mathrm{pH} 10$ was $31 \%$ at a PEX concentration of $1 \times 10^{-6} \mathrm{M}, 52 \%$ at $1 \times 10^{-5} \mathrm{M}$, and $71 \%$ at $1 \times 10^{-4} \mathrm{M}$.

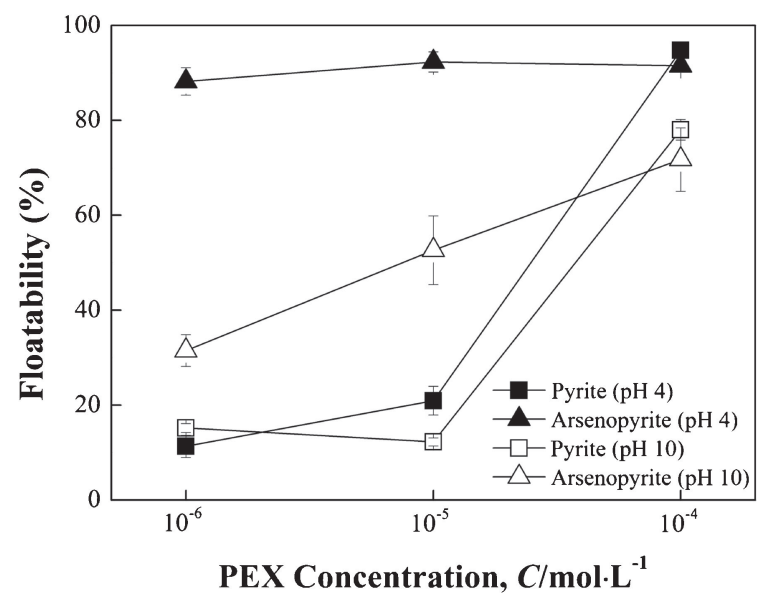

Fig. 2 Floatability of arsenopyrite (triangle) and pyrite (square), according to the potassium ethyl xanthate (PEX) concentration, at $\mathrm{pH} 4$ (solid) and 10 (blank). All experiments were conducted at $25^{\circ} \mathrm{C}$.

The floatability of pyrite at $\mathrm{pH} 10$ was $15 \%$ at a PEX concentration of $1 \times 10^{-6} \mathrm{M}, 12 \%$ at $1 \times 10^{-5} \mathrm{M}$, and $78 \%$ at $1 \times 10^{-4} \mathrm{M}$. In previous study, Gaudin (1957) performed flotation tests of arsenopyrite using xanthate as a collector, in which acidic $\mathrm{pH}$ at $\mathrm{pH} 5$ had the highest floatability. ${ }^{23)}$ Sutherland and Wark (1955) reported that the critical $\mathrm{pH}$ above which flotation did not occur was 8.4 for arsenopyrite, and 10.5 for pyrite. ${ }^{24)}$ Tapley (2003) reported that the floatability of arsenopyrite and pyrite at low $\mathrm{pH}$ was higher than that at high $\mathrm{pH}$, which showed a similar trend with the observed test results in the present study. ${ }^{19)}$

According to previous researches, in sulfide flotation using xanthate as a collector, the oxidation of xanthate ion in aqueous solution played an important role in the floatability, and the process of oxidation of xanthate ion into dixanthogen was greatly affected by the $\mathrm{pH}$ and $E_{\mathrm{H}}$ of pulp. ${ }^{19,25)}$ Thus, to fully understand the flotation behavior of arsenopyrite and pyrite in the present study, the pulp potential $\left(E_{\mathrm{H}}\right)$ was measured of pulp including arsenopyrite and pyrite at the same condition of flotation test (i.e., PEX concentration = $1 \times 10^{-6}-1 \times 10^{-4} \mathrm{M}, \mathrm{pH}=4$ and 10$)$.

\subsection{Analysis of correlation between the change of pulp potential $\left(E_{\mathrm{H}}\right)$ and flotation}

When xanthate ion $\left(\mathrm{X}^{-}\right)$is oxidized on the mineral surface and adsorbed on mineral surface as dixanthogen $\left(\mathrm{X}_{2}\right)$, it improves the hydrophobicity of the mineral, which resulted in an increase in floatability. ${ }^{20,21)}$ Previous studies reported that dixanthogen has a range of $E_{\mathrm{H}}$ that exists very stably. ${ }^{9,26)}$ Accordingly, to examine the correlation between floatability and $E_{\mathrm{H}}$ in the present study, the floatability of arsenopyrite and pyrite was plotted with the $E_{\mathrm{H}}$ function in Fig. 3. Figures 3(A) and (B) are a graph of $E_{\mathrm{H}}$ and the floatability change of arsenopyrite and pyrite, according to PEX concentration. As Fig. 3(A) shows, regardless of the $\mathrm{pH}$ and $E_{\mathrm{H}}$ value, the highest PEX concentration at $1 \times 10^{-4} \mathrm{M}$ showed the highest floatability of arsenopyrite. This is because along with the increase of xanthate concentration, the floatability increased, due to the enhancement of hydrophobic force between mineral and bubble. Meanwhile, under pH 4 condition, when the PEX concentration was $1 \times 10^{-6}$ 

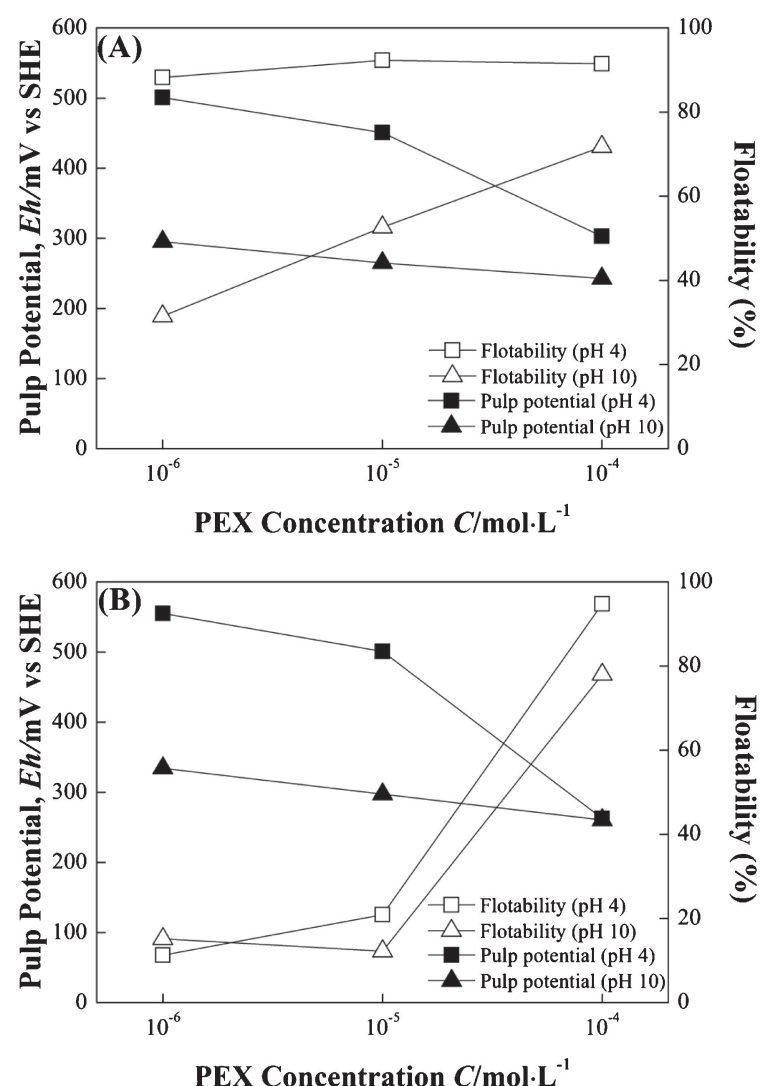

Fig. 3 Change of pulp potential (solid) and floatability (blank) of (A) arsenopyrite, and (B) pyrite, according to the PEX concentration, at $\mathrm{pH} 4$ (square) and 10 (triangle). All experiments were conducted at $25^{\circ} \mathrm{C}$.

and $1 \times 10^{-5}$, the $E_{\mathrm{H}}$ values of arsenopyrite pulp measured 500.8 and $450.7 \mathrm{mV}$ (vs SHE), which represents a stable range of dixanthogen as reported in a previous study, ${ }^{14)}$ resulting in the high floatability of arsenopyrite. However, in contrast, under $\mathrm{pH} 10$ condition, when the PEX concentrations were $1 \times 10^{-6}$ and $1 \times 10^{-5} \mathrm{M}$, the $E_{\mathrm{H}}$ values of arsenopyrite pulp were 295.3 and $264.9 \mathrm{mV}$ (vs SHE), which was beyond the range of stable existence of dixanthogen. ${ }^{27)}$ As such, the floatability of arsenopyrite at $\mathrm{pH} 10$ was relatively lower than that at $\mathrm{pH} 4$.

As Fig. 3(B) shows, similar to the arsenopyrite floatability result (Fig. 3(A)), the pyrite floatability was highest at a PEX concentration of $1 \times 10^{-4} \mathrm{M}$, regardless of the $\mathrm{pH}$ and $E_{\mathrm{H}}$ value. Meanwhile, under $\mathrm{pH} 10$ condition, when the PEX concentrations were $1 \times 10^{-6}$ and $1 \times 10^{-5} \mathrm{M}$, the $E_{\mathrm{H}}$ values of pyrite pulp were 334.3 and $297.3 \mathrm{mV}$ (vs SHE), respectively. As these values are beyond the stable scope of dixanthogen, as with the test result of arsenopyrite, the floatability was low. But, the interesting result is that despite the high $E_{\mathrm{H}}$ value at $\mathrm{pH} 4$ (i.e., despite the stable formation of dixanthogen), this shows that the pyrite floatability was low, which was not consistent with the observed trend of test results with arsenopyrite. To explain the reason for different trends of floatability of pyrite and arsenopyrite under a similar condition (i.e., a similar $E_{\mathrm{H}}$ range of stable formation of dixanthogen), surface analysis was carried out using FTIR spectroscopy of arsenopyrite and pyrite that were adsorbed with PEX $1 \times 10^{-6} \mathrm{M}$ under $\mathrm{pH} 4$. Figure 4 shows the results. For pyrite at $\mathrm{pH} 4$, it was confirmed that an $\mathrm{SO}_{4}{ }^{2-}$

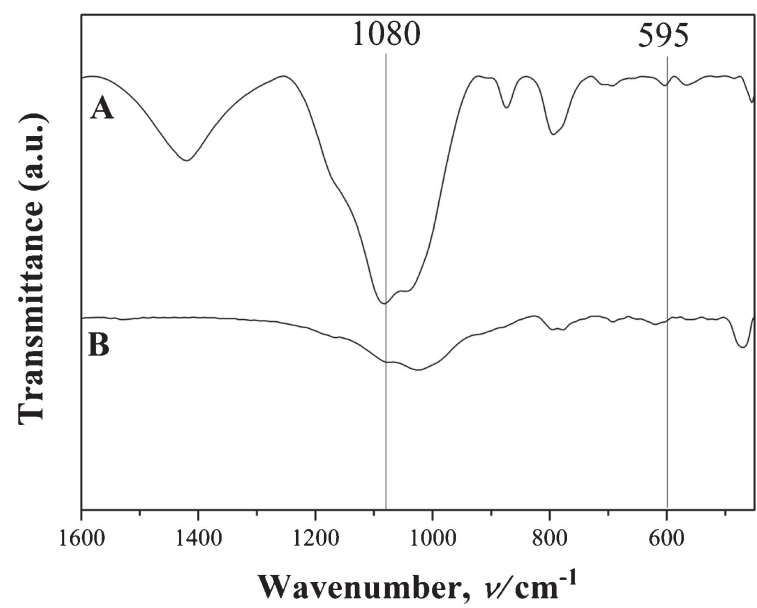

Fig. 4 Infrared (IR) spectra of (A) pyrite, and (B) arsenopyrite. The samples were treated with $10^{-6} \mathrm{M} \mathrm{PEX}$, at $\mathrm{pH} 4$ and $25^{\circ} \mathrm{C}$.

peak (strong peak at $1080 \mathrm{~cm}^{-1}$ and medium peak at 595 $\left.\mathrm{cm}^{-1}\right)^{9,28)}$ appeared clearly; but there was almost no $\mathrm{SO}_{4}{ }^{2-}$ peak for arsenopyrite. The trend is likely due to the difference of mineralogical structure of the two minerals. Specifically, according to the previous researches, sulfide ions on the surface of arsenopyrite and pyrite reacted with oxygen in pulp during agitation, and formed an $\mathrm{SO}_{4}{ }^{2-}$ layer on the mineral surface that inhibited adsorption with xanthate. ${ }^{29,30)}$ Based on the results from the previous study and the present study, the pyrite floatability was low because of poor adsorption with xanthate, since pyrite with simple mineralogical structure likely formed $\mathrm{SO}_{4}{ }^{2-}$ layer easily, via surface oxidation. In contrast, arsenopyrite with complicated mineralogical structure had relatively low surface oxidation that did not form an $\mathrm{SO}_{4}{ }^{2-}$ layer. ${ }^{9)}$ Thus, the adsorption with xanthate was effective, and the floatability was higher than that of pyrite.

\subsection{Selective flotation of arsenopyrite and pyrite}

When the correlations between the floatability and $E_{\mathrm{H}}$ of single minerals (i.e., arsenopyrite and pyrite) were examined, high $E_{\mathrm{H}}$ values appeared at low $\mathrm{pH}$ and low PEX concentration, and under the same condition, there was a high difference in floatability between arsenopyrite and pyrite. In order to further examine the flotation behavior of mixed sample (i.e., mixture of arsenopyrite and pyrite), flotation tests were performed with the mixed sample, by changing the PEX concentration $\left(5 \times 10^{-7}, 10^{-6}\right.$, and $\left.10^{-5} \mathrm{M}\right)$. The mixed ratio of the two minerals was fixed at $1: 1$, and the pulp $\mathrm{pH}$ was fixed at $\mathrm{pH} 4$. The selectivity indices (i.e., pyrite recovery/arsenopyrite recovery ratio), as well as the recoveries of arsenopyrite and pyrite were determined, and Fig. 5 presents the results. At $5 \times 10^{-7} \mathrm{M}$ PEX, the recoveries of arsenopyrite and pyrite were $9 \%$ and $61 \%$, respectively; at $10^{-6} \mathrm{M} \mathrm{PEX}$, the recoveries of arsenopyrite and pyrite were $22 \%$ and $71 \%$, respectively; and at $10^{-5} \mathrm{M}$ PEX, the recoveries of arsenopyrite and pyrite were $63 \%$ and $84 \%$, respectively. Meanwhile, the selectivity indices of the two minerals were 1.33 at $10^{-5} \mathrm{M}$ PEX, 3.16 at $10^{-6} \mathrm{M}$ PEX, and 6.4 at $5 \times 10^{-7} \mathrm{M}$ PEX. The results indicate that the selectivity index value increased with 


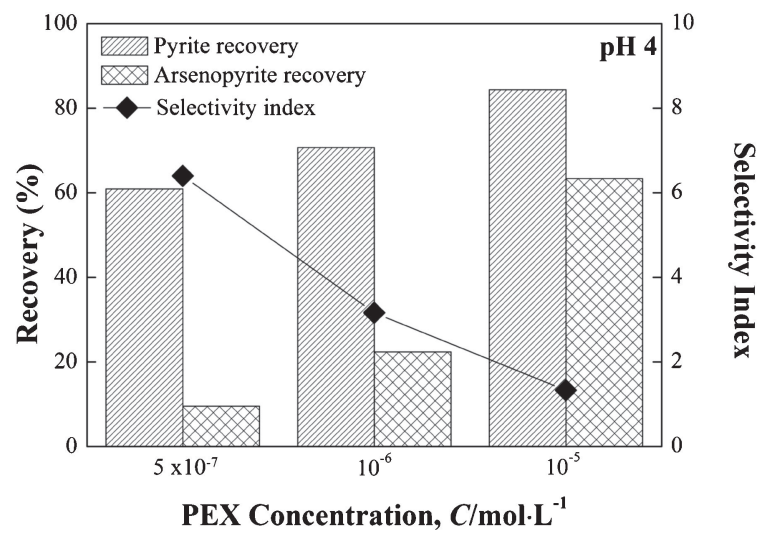

Fig. 5 Recovery and selectivity index for mixed sample of arsenopyrite and pyrite, according to the PEX concentration. The mixed ratio of arsenopyrite and pyrite was 1 to 1 , and all experiments were carried out at $\mathrm{pH} 4$ and $25^{\circ} \mathrm{C}$. The selectivity index is defined as the ratio of pyrite recovery and arsenopyrite recovery.

decreasing PEX concentration. Although it may not be directly comparable due to the difference in a scale of the system tested, it is still worth pointing out that the maximum selectivity index value $(\sim 6.4)$ from the present study was found to be greater than the greatest value $(\sim 4.2)^{18)}$ reported so far for similar mineral mixture. A previous study reported that arsenic sulfide was more affected by $E_{\mathrm{H}}$ than other sulfides without arsenic, when the flotation process was performed. ${ }^{14)}$ Based on the previous work, we also hypothesized that at high $E_{\mathrm{H}}$, arsenic oxide was formed on the surface of arsenopyrite, resulting in poor adsorption with xanthate. To confirm the hypothesis, XRD analysis was performed with a mixed sample under $5 \times 10^{-7} \mathrm{M}$ PEX condition, in which the selectivity index was the highest, and Fig. 6 presents the results. Figure 6(A) shows the XRD pattern of mixed sample of arsenopyrite and pyrite. For the purpose of comparison, the XRD patterns of raw pyrite and raw arsenopyrite are also presented in Figs. 6(B) and (C). No peak corresponding to ferric arsenate (denoted as $F)^{31)}$ was observed for raw pyrite (Fig. 6(B)) and arsenopyrite (Fig. 6(C)), but, as for the mixed sample treated with $5 \times 10^{-7} \mathrm{M}$ PEX at $\mathrm{pH} 4$, a peak of ferric arsenate was observed (Fig. 6(A)). According to the previous researches, through the oxidation reaction of arsenopyrite, arsenate anion $\left(\mathrm{AsO}_{4}{ }^{3-}\right)$ and ferric hydroxide $\left(\mathrm{Fe}(\mathrm{OH})_{3}\right)$ were initially formed, and then ferric arsenate was formed on the arsenopyrite surface, by the reaction between these oxide materials. ${ }^{32-34)}$ In particular, ferric arsenate is hydrophilic arsenic oxide, and has a very stable crystal structure at high $\left.E_{\mathrm{H} \cdot}{ }^{15}\right)$ Therefore, the low floatability of arsenopyrite is believed to result from poor adsorption of xanthate onto arsenopyrite, due to the ferric arsenate layer that forms on the arsenopyrite surface.

\section{Conclusions}

In the present study, the effects of $\mathrm{pH}$ and pulp potential $\left(E_{\mathrm{H}}\right)$ on the flotation behavior of arsenopyrite and pyrite were systematically investigated, by using xanthate as a collector, and the following conclusions were drawn:

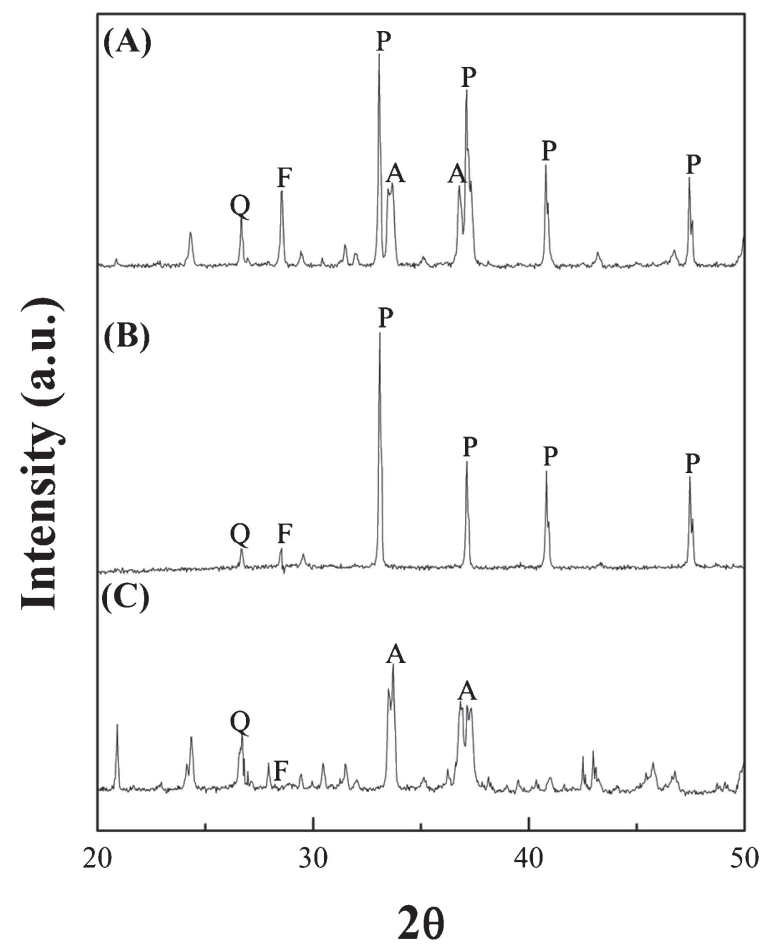

Fig. 6 XRD pattern for (A) mixed sample of arsenopyrite and pyrite, (B) raw pyrite, and (C) raw arsenopyrite (P: pyrite, A: arsenopyrite, Q: Quartz, and F: Ferric arsenate). The mixed sample was treated with $5 \times 10^{-7} \mathrm{M} \mathrm{PEX}$, at $\mathrm{pH} 4$ and $25^{\circ} \mathrm{C}$, and the mixed ratio of arsenopyrite and pyrite was 1 to 1 .

(1) For the flotation of a single mineral, the floatabilities of arsenopyrite and pyrite in the acidic $\mathrm{pH}$ range were relatively higher than in the alkali condition.

(2) The reason for higher floatability of arsenopyrite in acidic $\mathrm{pH}$ than alkali $\mathrm{pH}$ was that stable dixanthogen was adsorbed on the arsenopyrite surface, due to the high $E_{\mathrm{H}}$ value of pulp. Conversely, at alkali $\mathrm{pH}$ range, the arsenopyrite floatability was low, as dixanthogen was unstable, due to the low $E_{\mathrm{H}}$ value of pulp.

(3) The pyrite floatability was low at both acidic and alkali pHs. At alkali $\mathrm{pH}$ range, the floatability was low, as dixanthogen was unstable, which resulted in poor adsorption of xanthate onto the pyrite surface, due to the low $E_{\mathrm{H}}$ value of pulp. For the acidic $\mathrm{pH}$ condition, despite the high $E_{\mathrm{H}}$ value, adsorption with dixanthogen did not properly occur, due to the $\mathrm{SO}_{4}{ }^{2-}$ layer that formed on pyrite surface, via the reaction with oxygen in pulp.

(4) When flotation tests were performed by mixing arsenopyrite and pyrite at $1: 1$, the lowest PEX concentration had the highest selectivity index of arsenopyrite and pyrite. This was because ferric arsenate, a hydrophilic compound, created by the oxidation of arsenopyrite surface as arsenopyrite, was affected by the $E_{\mathrm{H}}$ more than was pyrite.

\section{Acknowledgements}

Both Kyuhyeong Park and Junhyun Choi equally contributed to this manuscript. This work was in part supported by the Korea Institute of Geoscience and Mineral Resources 
(KIGAM) funded by the Ministry of Knowledge Economy of Korea and the Global Ph.D Fellowship Program through the National Research Foundation of Korea (NRF) funded by the Ministry of Education (2014H1A2A1020346).

\section{REFERENCES}

1) J. C. Ng, J. P. Wang and A. Shraim: Chemosphere 52 (2003) 1353 1359.

2) P. Lattanzi, S. D. Pelo, E. Musu, D. Atzei, B. Elsener, M. Fantauzzi and A. Rossi: Earth Sci. Rev. 86 (2008) 62-88.

3) G. Long, Y. Peng and D. Bradshaw: Miner. Eng. 36-38 (2012) 179186.

4) P. L. Smedley and D. G. Kinniburgh: Appl. Geochem. 17 (2002) 517 568.

5) A. H. Smith, C. Hopenhaynrich, M. N. Bates, H. M. Goeden, I. Hertzpicciotto, H. M. Duggan, R. Wood, M. J. Kosnett and M. T. Smith: Environ. Health Persp. 97 (1992) 259-267.

6) G. Morizot and P. Ollivier: Miner. Eng. 6 (1993) 841-856.

7) P. C. Wilson and C. Chanroux: Cost Estimation Handbook for the Australian Mining Industry, ed. by M. Noakes and T. Lanz, (The Australian Institute of Mining and Metallurgy, 1993) pp. 325-368.

8) L. K. Smith and W. J. Bruckard: Int. J. Miner. Process. 84 (2007) 1524.

9) A. M. Abeidu and A. M. Almahdy: Int. J. Miner. Process. 6 (1980) 285-302.

10) W. T. Yen and J. Tajadod: Selective depression of enargite and chalcopyrite, Proc. of XXI Int. Miner. Process. Cong., Rome, ed. by P. Massacci, (2000) pp. 49-55.

11) J. M. Menacho, W. Aliaga, R. Valenuela, V. Ramos and I. Olivares: Minerals 48 (1993) 33-39.

12) R. O. Huch: Method for achieving enhanced copper-containing mineral concentrate grade by oxidation and flotation. U.S. Patent 5,295,585, (1994).

13) D. Fornasiero, D. Fullson and J. Ralston: Int. J. Miner. Process. 61 (2001) 109-119.

14) C. Kantar: Colloid. Surface A 210 (2002) 23-31.
15) A. López Valdivieso, A. A. Sánchez López, C. Ojeda Escamilla and M. C. Fuerstenau: Int. J. Miner. Process. 81 (2006) 27-34.

16) X. Ma and W. J. Bruckard: Int. J. Miner. Process. 93 (2009) 89-94.

17) G. W. Poling and J. V. Beattie: Selective depression in complex sulphide flotation, Principles of Mineral Flotation, ed. by M. H. Jones and J. T. Woodeock, (The Australian Institute of Mining and Metallurgy, Melbourne, 1984) pp. 137-146.

18) A. A. Sirkeci: Int. J. Miner. Process. 60 (2000) 263-276.

19) B. Tapley and D. Yan: Miner. Eng. 16 (2003) 1217-1220.

20) A. López Valdivieso, C. O. Escamila, S. Song, I. L. Baez and I. G. Martínez: Int. J. Miner. Process. 69 (2003) 175-184.

21) J. Choi, K. Park, J. Hong, J. Park and H. Kim: Meter. Trans. 54 (2013) 2291-2296.

22) J. Choi, J. Hong, K. Park, G. Kim, Y. Han, S. Kim and H. Kim: Mater. Trans. 55 (2014) 1344-1349.

23) A. M. Gaudin: Flotation, (McGraw-Hill, New York, N.Y., 1957) p. 552 .

24) K. L. Sutherland and I. W. Wark: Principles of Flotation, (Australian Institute of Mining and Metallurgy, Melbourne, 1955) p. 117.

25) R. Woods: Flotation of Sulfide Minerals, Reagents in Mineral Technology, Surfactant Science Series 27, ed. by P. Somasundaran and B. M. Moudgil, (Marcel Dekker Inc., New York, 1998) 39-78.

26) H. Guo and W. Yen: Miner. Eng. 18 (2005) 605-612.

27) W. J. Bruckard, I. Kyriakidis and J. T. Woodcock: Int. J. Miner. Process. 84 (2007) 25-32.

28) R. G. White: Handbook of Industrial Infrared Analysis, (Plenum Press, New York, N.Y., 1964) 178-218.

29) A. N. Buckley and R. Woods: Appl. Surf. Sci. 27 (1987) 437-452.

30) A. P. Chandra and A. R. Gerson: Adv. Colloid Interface Sci. 145 (2009) $97-110$

31) M. J. V. Beattie and G. W. Poling: Int. J. Miner. Process. 20 (1987) 87108.

32) Y. Jia, L. Xu, X. Wang and G. P. Demopoulos: Geochim. Cosmochim. Acta 71 (2007) 1643-1654.

33) M. B. M. Monte, A. J. B. Dutra, C. F. R. Alburqueque, L. A. Tondo and F. F. Lins: Miner. Eng. 15 (2002) 1113-1120.

34) M. Stefanakis and A. Kontopoulos: Arsenic Metallurgy: Fundamentals and Applications, ed. by R. G. Reddy, J. L. Hendrix and P. B. Quenau, (The Metallurgical Society, Inc., 1988) pp. 287-304. 